\begin{tabular}{|c|c|}
\hline Proceeding of the $9^{\text {th }}$ ICEE Conference 3-5 April 2018 & NBC \\
Military Technical College \\
Kobry El-Kobbah, \\
Cairo, Egypt
\end{tabular}

NBC -5

\title{
Evaluation of Chromium (Cr III) Adsorption using Modified Chitosan from Different pH Aqueous Solutions
}

Magdy A.Wassel1, Anwar.A.Wassel 2, Mahmoud Fathy3, Rasha Hosny4 and O.H. Abdelraheem5*

\begin{abstract}
Modified forms of chitosan beads were prepared and used for removal of trivalent chromium ( $\mathrm{Cr}$ III) from different $\mathrm{pH}$ aqueous media. Modified chitosan were characterized by using FTIR, X-ray diffraction (XRD) and Scanning Electron Microscopy (SEM). Adsorption experiments were carried out in a batch process and some experimental parameters (initial chromium ion (Cr III) concentration, contact time, $\mathrm{pH}$ and temperature) were optimized. The experimental results were fit well to the Langmuir isotherm and followed a pseudo-second order kinetic model. Thermodynamic parameters such as $\Delta \mathrm{H}, \Delta \mathrm{S}$ and $\Delta \mathrm{G}$ were calculated, indicating that the adsorption was spontaneous and endothermic nature.
\end{abstract}

\section{Keywords:-}

Modified Chitosan, Cr (III), pH effect, Adsorption Isotherm

1. Chemistry Department, Faculty of Science, Al-Azhar University, Cairo, Egypt

2. College of Sciences, University of Damman, KSA,

3. National Organization for Drug Control and Research, Giza-Egypt

4. Egyptian Petroleum Research Institute (EPRI). Cairo, Egypt,

5. Faculty of Engineering, Beni-Suef University, Egypt 
Military Technical College

Kobry El-Kobbah, Cairo, Egypt

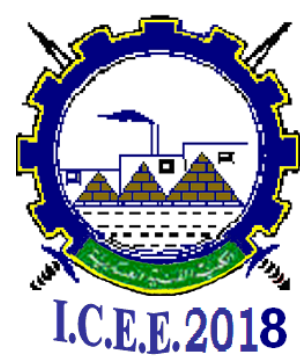

$9^{\text {th }}$ International Conference

on

Chemical \& Environmental

Engineering

3-5 April 2018

\section{Introduction}

As a result of increased industrial activities (mining operations, refining ores, sludge disposal etc), many heavy metals are released into the environment. Excessive release of heavy metals into the environment due to industrialization and urbanization has posed a great problem worldwide. Heavy metals are not degradable and have increasing significance owing to their harmful effect on human physiologies and other biological systems when they exceed the tolerance levels (Puvvada et al., 2012). Chromium as a heavy metal is ranked among the top sixteen toxic pollutants that have harmful effects on human health (Samson et al., 2016).

Trivalent chromium is said to be sorbed onto biosorbents by mechanisms like ion exchange, surface complexation or a combination of both depending on the biosorbent used and the available functional group (Han et al. 2008). Wide variety of adsorbents were used for chromium adsorption by researchers including cement kiln dust (Fadali et al., 2004), activated carbon (Mohan and Pittman 2006), Sawdust and modified peanut husk studied as adsorbents (Nasernejad et al., 2005), aquatic weeds (Elangovan et al. 2008), grape stalks and yohimbe bark (Fiol et al. 2008) and modified coconut husk (Olayinka, et al, 2009); among others; have been used. Among many biosorbents, chitosan can be an excellent biosorbent for metals because its amine (NH2) and hydroxyl $(-\mathrm{OH})$ groups may serve as coordination sites to form complexes with various heavy metal ions (Chauhan,et al., 2012). The reactive amino and hydroxyl groups in its linear polyglucosamine chains, can be used to functionalize and modify (Hosny et al. 2014; 2016). However, conventional modification method using single chitosan crosslinking with glutaraldehyde generally leads to decrease of functional group (-NH2-) and loading capacity, its interested to prepare multifunctional chitosan-x which used in many applications such as water treatment by using diethylenetria-mine pentaacetic acid (DTPA) with sufficient number of carboxyl groups on the backbones, is a commonly used as chelating agent for heavy metal (Wassel et al. 2013; 2015).

Naoki et al. (2014) performed adsorption experiment from aqueous solutions containing known amount of $\mathrm{Cr}$ (chromium) using chitosan, to evaluate the efficiency of chitosan as sorbent for Cr. Some variable parameters such as $\mathrm{pH}$, reaction time and chitosan dosage were optimized. The $\mathrm{Cr}$ (III) adsorption was strongly dependent on $\mathrm{pH}$ and adsorbent dosage, but independent of ionic strength and other metal ions Mohamed and Fahmy (2012) studied the effect of $\mathrm{pH}$ solution on biosorption of $\mathrm{Cr}$ (III), $\mathrm{Cu}$ (II) and $\mathrm{Zn}$ (II) from aqueous solution on carrot residues.

This current study investigates the variables that influence $\mathrm{Cr}$ (III) ions removal in acidic and basic medium by modified chitosan. 
Military Technical College

Kobry El-Kobbah,

Cairo, Egypt

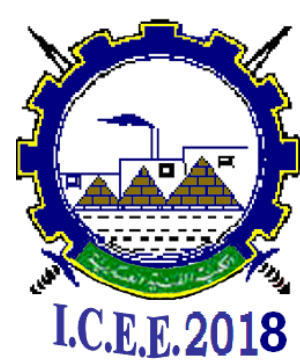

$9^{\text {th }}$ International Conference

on

Chemical \& Environmental

Engineering

3-5 April 2018

\section{Experimental}

\subsection{Materials and Methods}

\subsubsection{Materials}

Chitosan (MW 5000 Daltons) was purchased from Tako Kasei Kogyo CO. Ltd., Japan and used as received. Starch $(\mathrm{C} 6 \mathrm{H} 10 \mathrm{O} 5)$ n soluble GR was purchased from Merch chemicals India. Glutraldehyde (C5H8O2) (MW $100.12 \mathrm{gm}$ and density $1.13 \mathrm{Kg} / \mathrm{lit}$ ) was purchased from central Drug House, New Delhi, India. Sodium hexameta phosphate, a physical crosslinker of starch, was purchased from Pioneer chem Co. New Delhi. Other chemical were of analytical grade.

\subsubsection{Preparation of modified cross linked Chitosan}

$20 \mathrm{ml}$ of $2 \%$ acetic acid solution (in water) was taken in a beaker and a known quantity of chitosan was added slowly under stirring condition followed by stirring for about 2 hrs. A starch solution was prepared separately by dissolving a known quantity of starch in $10 \mathrm{ml}$ of water. The prepared starch solution was added into chitosan solution under stirring conditions and mixed together for $3 \mathrm{hrs}$ at room temperature. The prepared mixture was kept at room temperature $(293 \mathrm{~K})$ over night. Sodium hydroxide-methanol $(1: 20 \mathrm{w} / \mathrm{w})$ solution was prepared chitosan and starch solution was extruded through a syringe into a homogenous solution of sodium hydroxide- methanol at temperature. Freshly prepared beads were washed thrice with distilled water and resultant beads were allowed to reach with $20 \mathrm{ml}$ of sodium hexameta phosphate (SHMP) 25\% solution for 10 minutes at room temperature. Physically cross linked beads were washed and dipped into $20 \mathrm{ml}$ of glutraldehyde (GA) $(25 \%)$ solution for 10 minutes at $333 \mathrm{~K}$. Finally, the cross linked beads were washed with distilled water and dried in oven at $313 \mathrm{~K}$ for $12 \mathrm{hrs}$ (Xu et al. 2005).

\subsection{Characterization of modified cross linked Chitosan}

\subsubsection{FTIR}

The infrared spectra of modified chitosan sample was then analyzed using Shimadzu $6100 \mathrm{~A}$ spectrometer and the spectrum was recorded in a spectral range of $400-4000 \mathrm{~cm}-$ 1 , using $\mathrm{KBr}$ disc method.

\subsubsection{XRD}

A pan analytical X-Ray Diffraction equipment model X-Pert with secondary monochromator, Cu-radiation $(\lambda=1.542 \AA$ ) at 45 K.V., 35 M.A. and scanning speed $0.02 \mathrm{o} / \mathrm{sec}$. were used. The diffraction peaks between $2 \theta=0 \mathrm{o}$ and $60 \mathrm{o}$, corresponding spacing $(\mathrm{d}, \AA)$ and relative intensites (I/Io) were obtained. The diffraction charts and relative intensities are obtained and compared with ICDD files of solid chitosan and modified chitosan recorded. 
Military Technical College

Kobry El-Kobbah,

Cairo, Egypt

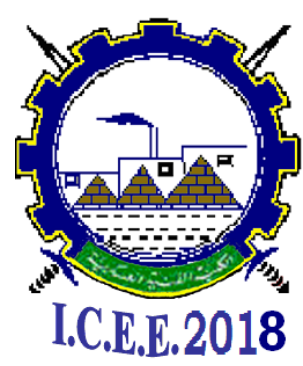

$9^{\text {th }}$ International Conference

on

Chemical \& Environmental

Engineering

3-5 April 2018

\subsubsection{SEM}

The Scanning Electron Microscope examination for chitosan and modified chitosan samples performed using SEM Model Quanta 250 FEG (Field Emission Gun) attached with EDX Unit (Energy Dispersive X-ray Analyses), with accelerating voltage $30 \mathrm{~K}$.V., magnification14x up to 1000000 and resolution for Gun.1n). FEI Company, Netherlands.

\subsection{Study of the adsorption kinetics modeling}

\subsubsection{Effect of Temperature}

Effect of temperature on the adsorption kinetics evaluated by batch experiments contacting a constant mass $(0.5 \mathrm{~g})$ of modified chitosan with a fixed volume $(50 \mathrm{ml})$ of concentration $(300 \mathrm{ppm})$ for different intervals of contact time $(30,60,90,120 \mathrm{~min})$ at different temperatures $\left(25,35\right.$ and $\left.45^{\circ} \mathrm{C}\right)$.

\subsubsection{Effect of pH}

The study of $\mathrm{pH}$ effect on adsorption during kinetic study was performed at $\mathrm{pH} 2,3$, 4,7,8,9 and 10 using the same condition of kinetic study (an adsorbent dose of $0.5 \mathrm{~g}$ and $\mathrm{Cr}$ solutions volume $50 \mathrm{ml}$ at 25,35 and $45^{\circ} \mathrm{C}$ ). The $\mathrm{pH}$ of the initial solution was adjusted by using $\mathrm{HCl}$ and $\mathrm{NH} 4 \mathrm{OH}$.

\subsection{Adsorption Isotherm}

Batch equilibrium isotherm was carried out in the same manner. Solutions $(50 \mathrm{ml})$ of Chromium Cr (III) ions (20-300 ppm) were thermo stated at the required temperature in $250 \mathrm{ml}$ wide-mouth propylene test bottles with screw closure caps. A known mass $(0.5 \mathrm{~g})$ of the modified chitosan was added into each bottle, which shaken continuously for 120 min. The solution samples were withdrawn and filtered. The final concentration of Chromium (III) was determined in the filtrate by using atomic absorption (Thermo Fisher Scientific).

\subsubsection{Langmuir isotherm}

Langmuir isotherm is often used to describe adsorption of solute from liquid solutions and this model assumes monolayer adsorption onto a homogeneous surface with finite number of identical sites and expressed by the following Eq. (1).

$$
\mathrm{q}_{\mathrm{e}}=\frac{\mathrm{Q}_{\mathrm{o}} \mathrm{kL}_{\mathrm{L}} \mathrm{C}_{\mathrm{e}}}{1+\mathrm{k}_{\mathrm{L}} \mathrm{C}_{\mathrm{e}}}
$$

Characteristic constants of Langmuir equation, Qo the theoretical maximum adsorption capacity and $\mathrm{kL}$ related to affinity of the binding sites, Qo and kL Langmuir isotherm constants can be determined from the linearized of $\mathrm{Eq}(8)$ as in $\mathrm{Eq}(2)$ : 
Military Technical College

Kobry El-Kobbah,

Cairo, Egypt

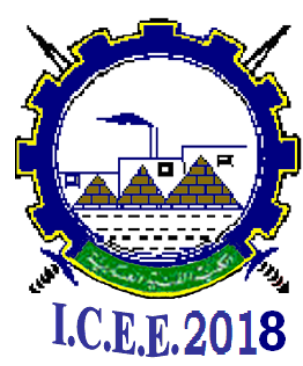

$$
\frac{C_{e}}{q_{e}}=\frac{1}{\mathrm{bQo}}+\frac{C_{e}}{\mathrm{Qo}}
$$

$9^{\text {th }}$ International Conference

on

Chemical \& Environmental

Engineering

3-5 April 2018

The slope and intercept of the linear plot of (Ce/qe) Verses (Ce) give the values of Qo and $\mathrm{kL}$ respectively. In order to know the feasibity of the isotherm, the essential features of Langmuir model can be expressed in the terms of separation factor or equilibrium parameter RL, which was defined by Eq (3):

$$
R_{L}=\frac{1}{1+b \cdot C_{0}}
$$

The values of RL indicate the shapes of isotherms to be either unfavorable (RL>1), linear $(R L=1)$, favorable $(0<R L<1)$ or irreversible $(R L=0)$ [17]. The $R L$ values for $\mathrm{Cr}$ (III) were calculated and indicated that adsorption is even favorable for the higher metal ion concentration that have been investigated. The data of RL values the adsorbent is suitable adsorbent (modified chitosan) for the adsorption of $\mathrm{Cr}$ (III) ions from aqueous solutions.

\subsubsection{Fruendlich isotherm}

The Freundlich mode is expressed as follows Eq. (4):

$$
\mathrm{q}_{\mathrm{e}}=\mathrm{K}_{\mathrm{F}} \cdot \mathrm{C}_{\mathrm{e}}^{1 / \mathrm{n}}
$$

The linearized form of Freundlich equation is given by Eq. (5):

$$
\log \mathrm{q}_{\mathrm{e}}=\log \mathrm{K}_{\mathrm{F}}+(1 / \mathrm{n}) \log \mathrm{C}_{\mathrm{e}}
$$

Where $\mathrm{Kf}$ and $1 / \mathrm{n}$ are characteristic constants representing the adsorption capacity and the adsorption intensity of the system respectively. The linear plot between (ln qe) verses (ln $\mathrm{Ce}$ ) gives a slope which is equal to the value of $(1 / \mathrm{n})$ and intercept is $(\ln \mathrm{kf})$. The magnitude of $0<n<1$ indicates the favorability of process of adsorption.

\subsubsection{Temkin and Pyzhev isotherm:}

The Temkin and Pyzhev isotherm has commonly been applied in the following Eq. (6).

$$
\begin{gathered}
q_{e}=\frac{R T}{b_{T}}\left(\ln A_{T} C_{e}\right) \\
q_{e}=B_{T} \ln A_{T}+B_{T} \ln \left(C_{e}\right) \\
B_{T}=\frac{R T}{b_{T}}
\end{gathered}
$$

Where (AT) $(\mathrm{L} / \mathrm{g})$ and $(\mathrm{bT})(\mathrm{J} / \mathrm{mol})$ are Temkin isotherm constants, (R) is the gas constant $(8.314 \mathrm{~J} / \mathrm{mol})(\mathrm{T})$ is the absolute temperature. (bT) related to heat of adsorption. 
Military Technical College Kobry El-Kobbah, Cairo, Egypt

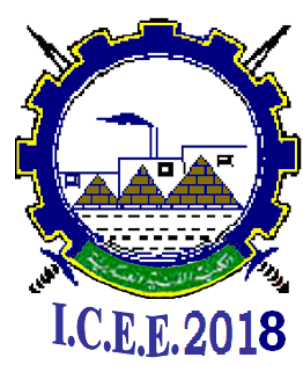

$9^{\text {th }}$ International Conference

on

Chemical \& Environmental

Engineering

3-5 April 2018

\subsubsection{Dubinin-Radushkevich isotherm}

The Dubinin-Radushkevich (D-R) isotherm (Jadhoo et al. 2008) was also employed to find out the adsorption mechanism based on the potential theory assuming a heterogeneous surface. Dubinin-Radushkevich isotherm is expressed as follows Eq.

$$
\mathrm{q}_{\mathrm{e}}=\mathrm{X}_{m} \mathrm{e}^{-\mathrm{pec} 2}
$$

The liner form was Eq. (10):

$$
\log \mathrm{q}_{\mathrm{e}}=\log \mathrm{X}_{\mathrm{m}}-\beta \varepsilon^{2}
$$

Where $(\mathrm{Xm})$ is the Dubinin-Radushkevich monolayer capacity $(\mathrm{mg} / \mathrm{g}),(\beta)$ is a constant related to adsorption energy, and $(\varepsilon)$ is the polanyi potential (Tripathi et al. 2009) which is related to the equilibrium concentration as follows in Eq. (11):

$$
\varepsilon=R T \ln \left(1+\left(1 / \mathrm{C}_{\mathrm{e}}\right)\right)
$$

Where $(\mathrm{R})$ is the gas constant $(8.314 \mathrm{~J} / \mathrm{mol} \mathrm{K})$ and $(\mathrm{T})$ is absolute temperature

A plot of (ln qe) Vs $(\varepsilon 2)$ as in gave a straight line of slope, $(\beta)$ and intercept, $(\mathrm{Xm})$ of different systems were evaluated. The difference in the free energy between the adsorbed phase and the saturated liquid adsorbate is referred to as the potential, a term first advanced by Polanyi (Bulut and Tez 2007). In the present study Dubinin-Radushkevich isotherm constants, monolayer capacity $(\mathrm{Xm})$ and adsorption energy $(\beta)$ are tabulated in Table (2). The magnitude of $(\beta)$ is used to determine the type of adsorption mechanism. When one mole of $\mathrm{Cr}$ (III) ions is transferred the adsorbent surface, its value is higher than $8.0 \mathrm{KJ} / \mathrm{mol}$ which indicates chemical adsorption.

\subsection{Kinetic studies of the adsorption processes for Chromium $\mathrm{Cr}$ (III)}

Rate of adsorption process were at temperature (To describe the kinetic process, kinetic data were analyzed based on Lagergren pseudo first-order model and pseudo second order reaction rate model ( $\mathrm{Ge}$ et al. 2012). The mathematical representations of these models are given in Eqs. (1) and (2) as the following:

\subsubsection{Pseudo first-order adsorption kinetic model:}

$$
\log \left(q_{1}-q_{t}\right)=\log q_{1}-\frac{k_{1}}{2.303} t
$$

Where (qt) is the amount of metal ion adsorbed at time (t).The adsorption rate constant (k1) (min-1) were calculated from the slope of linear plot of log (qe-qt) versus time (t). 
Military Technical College Kobry El-Kobbah, Cairo, Egypt

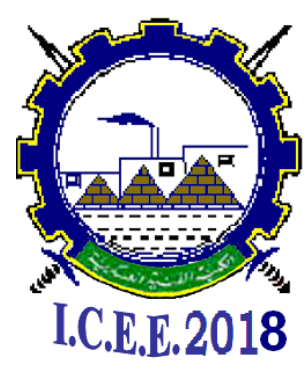

$9^{\text {th }}$ International Conference

on

Chemical \& Environmental

Engineering

3-5 April 2018

2.5.2 Pseudo second-order adsorption kinetic model:

$$
\frac{t}{q_{t}}=\frac{1}{q_{2}^{2} k_{2}}+\frac{t}{q_{2}}
$$

Kinetic model were plotted between $(\mathrm{t} / \mathrm{q} t)$ against $(\mathrm{t})$. The rate constant of intraparticle diffusion (kid) at different temperatures were determined using the following equation:

$$
q_{t}=K_{I} t^{0.5}
$$

Where (qt) is the amount adsorbed at time $t,(t 1 / 2$ ( is the square root of time

\subsection{Thermodynamic of the adsorption processes for chromium $\mathrm{Cr}$ (III)}

The effect of temperature on adsorption is further confirmed by the vant Holf plots as based on the equations (15, 16, 17 and 18) (Krishanan and Anirudhan 2002):

$$
\begin{gathered}
\mathrm{k}_{\mathrm{D}}=\mathrm{q}_{\mathrm{e}} / \mathrm{C}_{\mathrm{e}} \\
\Delta \mathrm{G}=-\mathrm{RT} \ln \mathrm{k}_{\mathrm{D}} \\
\Delta \mathrm{G}=\Delta \mathrm{H}-\mathrm{T} \Delta \mathrm{S} \\
\ln \mathrm{k}_{\mathrm{D}}=(\Delta \mathrm{S} / \mathrm{R})-(\Delta \mathrm{H} / \mathrm{RT})
\end{gathered}
$$

Where $(\mathrm{T})$ is absolute temperature in Kevin $(\mathrm{K}), \mathrm{R}$ is gas constant $(8.314 \mathrm{~J} / \mathrm{mol} \mathrm{K})$ and $\mathrm{kD}$ is the distribution coefficient $(\mathrm{ml} / \mathrm{g})$. The thermodynamic parameters namely enthalpy change $(\Delta \mathrm{H})$ and entropy change $(\Delta \mathrm{S})$ can be calculated from the slope and intercept of straight line plotted by (ln $\mathrm{kD})$ versus $(1 / \mathrm{T})$. The Gibbs free energy change $(\Delta \mathrm{G})$ was determined

\section{Results and Discussion}

\subsection{Characterization of modified chitosan}

\subsubsection{FTIR Spectroscopy}

The FTIR spectrum Fig. 1(a) of blended beads shows a broad band around 3600-3200 $\mathrm{cm}-1$, enhanced hydrogen bonding compared that of chitosan or starch alone. In the spectrum of starch and chitosan blend, the amino group peak of chitosan shifted from 1634 to $1650.245 \mathrm{~cm}-1$. This phenomenon pointed out that interactions were present between the hydroxyl group of starch and amino group of chitosan (Meenakshi et al. 2002; Mohamed and Fahmy 2012). In the spectrum of starch and chitosan blend, the amino group peak of chitosan shifted from 1634 to $1634.5,1636.3$ and1636.7 cm-1 in low acidic medium ( $\mathrm{pH}=4)$ Fig. (1d), low basic medium $(\mathrm{pH}=8)$ Fig. (1c) and aqueous medium ( $\mathrm{pH}=7)$ Fig.1 (b) respectively. 
Military Technical College

Kobry El-Kobbah, Cairo, Egypt

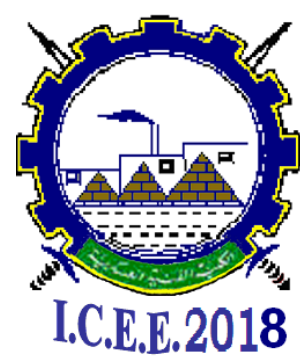

$9^{\text {th }}$ International Conference

on

Chemical \& Environmental

Engineering

3-5 April 2018

\subsubsection{X-ray Diffraction Analysis (XRD)}

The X-ray diffraction analysis for modified chitosan, the characteristic peaks at $2 \theta=10^{\circ}$ and $20^{\circ}$ disappeared, and a very weak and broad peak centered at $2 \theta=15^{\circ}$ appeared Figure (2). This difference in XRD patterns weak and broad peak centered at $2 \theta=15^{\circ}$ appeared Fig. (2). This difference in XRD patterns between chitosan and modified chitosan should be attributed to the cross-linking reaction between chitosan and glutaraldehyde. In agreement with the result of previous studies (Tripathi et al. 2009; Saita et al. 2012), the crystallinity of modified chitosan decreases after crosslinking with starch and glutaraldehyde. This could be attributed to the deformation of the strong hydrogen bond in original chitosan due to the substitution of hydroxyl and amino groups, which efficiently destroyed the regularity of thepacking of the original chitosan chains and resulted in the formation of amorphous modified chitosan. Recently, revealed that the incorporation of hydrophilic cross-linker into chitosan allowed the synthesis of hydrogels with higher hydrophilicity which is able to facilitate the active surface area that plays a very important role in adsorption process in our study (Suguna et al. 2011).

\subsubsection{Scanning electron microscope (SEM):}

The porous structure of modified chitosan in this study may offer more adsorption sites for adsorbate, which generally supported the fact that starch glutaraldehyde-crosslinked chitosan has been widely applied in the uptake of heavy metals (Varmaa et al. 2004; Aranaz et al. 2009). In addition, modified chitosan with a higher total surface area and a more open pore structure could be supposed to adsorbate Cr (III), which may at least partially explain this result that the adsorption by modified chitosan, but not solid chitosan Fig. (3)

\subsection{Equilibrium modeling at different $\mathrm{pH}$}

The adsorption parameters obtained from the four applied isotherms (Langmuir, Freundlich, Redlich-Peterson abd D-P). The results tabulated in Tables (1) and (2) at different $\mathrm{pH}$. The experimental data were fitted well with Langmuir isotherm suggesting that the $\mathrm{Cr}$ (III) adsorbed from monolayer coverage on the adsorbent surface. To lesser extent, the equilibrium data were also well described with the Freundlich model probably due to the real heterogeneous nature of the surface sites involved in the process of adsorption and thus indicating the applicability of monolayer coverage of the $\mathrm{Cr}$ (III) ions on the surface of adsorbent. This can be explained by the fact that the adsorbent have a high surface area for $\mathrm{Cr}$ (III) ions adsorption. Therefore only monolayer adsorption occurred on their surface (Zhanga et al. 2009).

Temkin E Values higher than 8 indicates strong interaction between $\mathrm{Cr}$ (III) and adsorbent. However, higher value indicates presence of relatively stronger cohesive forces in between the adsorbent and $\mathrm{Cr}$ (III).

Through the acidity range from 0.001 to $0.005 \mathrm{M} \mathrm{HCl}$, chromium ions $\mathrm{Cr}$ (III) adsorption capacity decreases. However, at further higher acid molarities unfavorable conditions are found to exist for adsorption, accordingly, no adsorption occur. This trend was observed 
Military Technical College

Kobry El-Kobbah, Cairo, Egypt

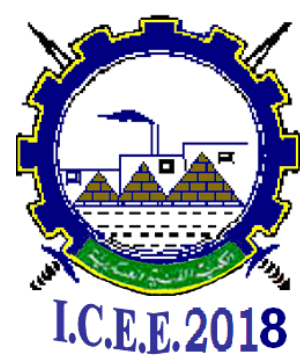

$9^{\text {th }}$ International Conference

on

Chemical \& Environmental

Engineering

3-5 April 2018

by earlier workers when examining metal adsorption no different adsorbents (Xiongaet al. 2011), and can be interpreted as follows. Under acidic conditions, as strong competition effect between $\mathrm{H}+$ and chromium $\mathrm{Cr}$ (III) caused by high concentration of $\mathrm{H}+$ leads to decrease amount of $\mathrm{Cr}$ (III) immobilized onto the modified chitosan. Furthermore, at high acidic the function groups are present in protonated forms which have electrostatic repulsion to chromium ions ( $\mathrm{Cr}$ (III)) and are hard to donor their electron pair to coordinate with chromium ions ( $\mathrm{Cr}$ (III)), thus weakening the complexation between them and further decreasing the chromium ions (Cr (III)) adsorption capacity. With the decrease of solution acidity, due to the decrease of $\mathrm{H}+$ concentration, the competition effect between $\mathrm{Cr}$ (III) (and/or $\mathrm{Cr}(\mathrm{OH}+)$ and $\mathrm{H}+$ becomes weak, resulting in more $\mathrm{Cr}$ (III) immobilized onto the modified chitosan.

Besides, the combined $\mathrm{H}+$ ions gradually dissociate from functional groups at low acidity, enhancing the complexation between $\mathrm{Cr}$ (III) and the functional groups, accordingly, and increase of $\mathrm{Cr}$ (III) uptake. According to the above presented assumption of complexation conditions, the modified chitosan process of $\mathrm{Cr}$ (III) complexes in $\mathrm{Cr}$ (III)-inorganic acid (hydrochloric acid) systems can be as follows:

$$
\text { (modified chitosan) } \left.) \cdot \mathrm{H}^{+}+\mathrm{Cr}(\mathrm{III}) \rightleftharpoons \text { (modified chitosan }\right) \mathrm{Cr}(\mathrm{III})+3 \mathrm{H}^{+}
$$

The calculated values of (E) for the present study is higher than $8.0 \mathrm{KJ} / \mathrm{mol}$ for the adsorption of $\mathrm{Cr}$ (III), which suggest that adsorption process onto the surface of the adsorbent modified chitosan is following chemical adsorption type.

The adsorption capacity of chitosan for $\mathrm{Cr}$ (III) increased with increasing $\mathrm{pH}$ to a maximum value at $\mathrm{pH} 4$, and then slightly decreasewith further increasing of $\mathrm{pH}$.

\subsection{Adsorption kinetics modeling in aqueous solution}

The data of the kinetics of $\mathrm{Cr}$ (III) adsorbed from aqueous solution onto modified chitosan were analyzed using pseudo first order, pseudo second order intraparticle diffusion kinetic models, respectively. The conformity between experimental data and each model predicted values was expressed by the correlation coefficient (R2). A relatively high (R2) values indicated that the model successfully describes the kinetics of $\mathrm{Cr}$ (III) ions adsorption removal.

The adsorption kinetics of $\mathrm{Cr}$ (III) ions from liquid phase to solid is considered as a reversible reaction with an equilibrium state being established between two phases.

Plots for Eq. (12) were made for the $\mathrm{Cr}$ (III) ions adsorption at different studied temperature. Approximately linear fits were observed for the $\mathrm{Cr}$ (III) ions, over the entire range of shaking time explored and at all temperatures with low correlation coefficient as in Table (3), indicating that the pseudo first order kinetic model is not valid for the present systems. and that the overall rate constant of each $\mathrm{Cr}$ (III) ion appears to be controlled by the chemisorptions process. 
Military Technical College

Kobry El-Kobbah, Cairo, Egypt

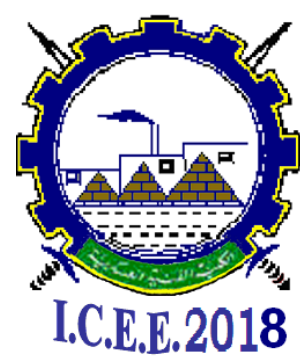

$9^{\text {th }}$ International Conference

on

Chemical \& Environmental

Engineering

3-5 April 2018

\subsection{Study the intra-particle diffusion model (weber-marries) in aqueous solution}

The (kid) values were obtained as in Table (4) from the slope of the linear portions of the curve of different initial concentration of the $\mathrm{Cr}$ (III) ions in aqueous solution. It can be seen that the plots possess multilinear portions; it indicates that the two or more steps influence the adsorption process. It was found that straight lines relate the points, the sharp first linear portion is due to the film diffusion and the second linear portion is due to the pore diffusion. Non-linearity of the plots had indicated the multi stage adsorption of toxic metal as $\mathrm{Cr}$ (III) by the adsorbent. The extrapolation of the first linear portion gives the intercept equal to the boundary layer thickness or film thickness. The values of intercept give an idea about the boundary layer thickness such as the layer the intercept, the greater the boundary layer effect.

It can be seen that the plots possess multilinear portions; it indicates that the two or more steps influence the adsorption process. It was found that straight lines relate the points, the sharp first linear portion is due to the film diffusion and the second linear portion is due to the pore diffusion. Non-linearity of the plots had indicated the multi stage adsorption of toxic metal as $\mathrm{Cr}$ (III) by the adsorbent. The extrapolation of the first linear portion gives the intercept equal to the boundary layer thickness or film thickness. The values of intercept give an idea about the boundary layer thickness such as the layer the intercept, the greater the boundary layer effect

\subsection{Study the effect of temperature and calculation of activation energy (Ea) in aqueous solution}

The above results were further substantiated by the various thermodynamic parameters. Enthalpy change $(\Delta \mathrm{H})$, Entropy change $(\Delta \mathrm{S})$, Gibbs free energy change $(\Delta \mathrm{G})$ and Activation energy (Ea) evaluated for adsorption.

The adsorption of $\mathrm{Cr}$ (III) ions has been found to increase with an increase in temperature from $(25$ to $45 \mathrm{oC}$ ). The increase in adsorption capacity of the adsorbent with temperature indicates an endothermic process. The obtained thermodynamic parameters $(\Delta \mathrm{H}, \Delta \mathrm{S}, \Delta \mathrm{G}$ and Ea) were listed in Table (3).

The increase in adsorption with temperature may be attributing to either change in pore size of the adsorbent causing inter-particle diffusion within the pores or to enhancement in the chemical affinity of the $\mathrm{Cr}$ (III) ions to the surface of adsorbent leading to some kind of chemical interaction to take during adsorption process which results into increase in adsorption capacity. At higher temperature, the possibility of diffusion of solute within the pores of adsorbent may not ruled out as reposted by earilier warkers (Weber and Morris 1963).

Therefore the positive value of $\Delta \mathrm{S}$ suggested some structure change in the adsorbent and adsorbate. In fact, the positive value of enthalpy $(\Delta \mathrm{H})$ further confirmed the endothermic nature of the processes, so increasing temperature supplied with a more favorable adsorption of $\mathrm{Cr}$ (III) ions onto the adsorbent. The negative Gibbs free energy $(\Delta \mathrm{G})$ value 
Military Technical College

Kobry El-Kobbah, Cairo, Egypt

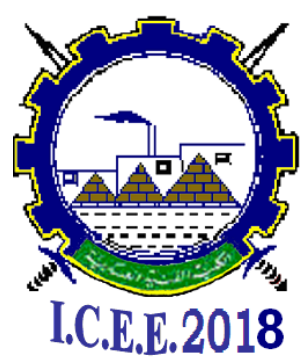

$9^{\text {th }}$ International Conference

on

Chemical \& Environmental

Engineering

3-5 April 2018

for the metal adsorption process on the adsorbent indicates the spontaneous nature of the adsorption process.

Generally, the values of the change in enthalpy $(\Delta \mathrm{H})$ indicated that adsorption process of Cr (III) is physical in nature (Aksu and Karabbauir 2008). The activation energy (Ea) was calculated by the linearized Arrhenius equation Eq. (19):

$$
\ln (\mathrm{k})=\ln (\mathrm{A})-(\mathrm{Ea} / \mathrm{RT})
$$

Where (Ea) I the activation energy of adsorption (kJmol-1), (k) is the rate constant which control the process, (A) is Arrhenius constant, (R) is the ideal gas constant and (T) is the absolute temperature $(\mathrm{K})$.

From the pseudo second-order kinetic studies, k2 is the rate constant which control the process, i.e (k) In this study, activation energy (Ea) value of different systems under study $(\mathrm{KJ} / \mathrm{mol})$ was obtained from the plot of $(\ln \mathrm{k} 2)$ versus $(1 / \mathrm{T})$. In physical adsorption, the activation energy (Ea) usually more than $8.0 \mathrm{KJmol}-1$, since the forces involved in chemical adsorption is high.

Chemical adsorption involves forces much stronger than in physical adsorption and the activation energy (Ea) is between (8.4) and (83.7) KJmol-1 (Weber and Morris 1963) noted that chemical adsorption includes activated and non-activated forms.

The results show that the process is one of activated chemical adsorption and the positive value of the activation energy (Ea) suggested that the rise in the solution temperature favors the $\mathrm{Cr}$ (III) ions adsorption onto the modified chitosan.

\section{Conclusion}

In this paper, modified chitosan was prepared and characterized by FTIR, XRD and SEM to confirm the functional groups and the morphological structure, respectively. The effect of various parameters has been investigated by the following batch adsorption technique. The obtained results showed that adsorption kinetics of $\mathrm{Cr} 3+$ onto modified chitosan followed the pseudo-second order model and the adsorption isotherm was well fitted by the Langmuir model. Thermodynamic parameters such as $\Delta \mathrm{H}, \Delta \mathrm{S}$ and $\Delta \mathrm{G}$ were calculated, indicating that the adsorption was spontaneous and endothermic nature.

\section{References:}

[1] Aksu Z. and Karabbauir. G. "Comparison of biosorption properties of different kinds of fungi for the removal of Gryfalan Black RL metal-complex dye", Bioresource Technol, 99, (2008), 77350-7741.

[2] Anoop Krishnan K1, Anirudhan TS., "Removal of mercury(II) from aqueous solutions and chlor-alkali industry effluent by steam activated and sulphurised activated carbons prepared from bagasse pith: kinetics and equilibrium studies"., J Hazard Mater. 2002 May 27;92(2):161-83. 
Military Technical College

Kobry El-Kobbah, Cairo, Egypt

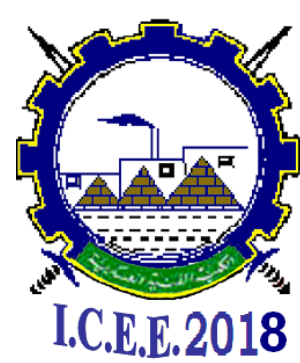

$9^{\text {th }}$ International Conference

on

Chemical \& Environmental

Engineering

3-5 April 2018

[3] Aranaz, I., Mengibar, M., Harris, R., Panos, I., Miralles, B., Acosta, N. and Galed, G., "Functional Characterization of Chitin and Chitosan", Curr. Chem. Biol., 3 (2009), 203-230.

[4] Bulut, Y. and Tez, Z. "Adsorption studies on ground shells of hazelnut and almond”, J. Hazard. Mater, 149, (2007), 35-41.

[5] Chauhan, D.; Jaiswal, M.; Nalini, S. Removal of Cadmium and Hexavalent Chromium from Electroplating Waste Water Using Thiocarbamoyl Chitosans. Carbohydrate Polymers 2012, 88, 670-675.

[6] Elangovan R, Philip L, Chandraraj K (2008) Biosorption of chromium species by aquatic weeds: kinetics and mechanism studies. J Hazard Mater 152(1):100-112.

[7] Fadali O. A. Fadali, Y. H. Magdy, A. A. M. Daifullah, E. E. Ebrahiem \& M. M. Nassar, Removal of Chromium from Tannery Effluents by Adsorption, Journal of Environmental Science and Health, Part A Vol. 39 , Iss. 2, 2004.

[8] Fiol N, Escudero C, Villaescusa I (2008) Chromium sorption and Cr(VI) reduction to $\mathrm{Cr}$ (III) by grape stalks and yohimbe bark. Bioresour Technol 99(11):5030-5036

[9] Ge, H. C., Chen, H. and Huang, S. Y.; J. Appl. Polym. Sci., 125 (2012), 2716-2723.

[10] Han X, Wong YS, Tam NFY (2006) "Surface complexation mechanism and modeling in $\mathrm{Cr}(\mathrm{III})$ biosorption by a microalgal isolate, Chlorella miniata." J Colloid Interf Sci 303(2):365-371

[11] Hosny, R., Abdel-Moghny, Th., Ramzi, M., Desouky, S.E.M. and Shama, S. A. "Preparation and Characterization of Natural Polymer for TreatmentProduced Water" International Journal of Current Research, Vol. 6, Issue, 03, pp.5413-5418, March, (2014).

[12] Hosny, R., Fathy, M., Ramzi, M., Moghny, T.A., Desouky, S.E.M. and Shama, S.A. "Treatment of the oily produced water (OPW) using coagulant mixtures", Egyptian Journal of Petroleum, Vol. , Issue, pp. 391-396 (2016).

[13] Jadhoo, M. M., Palinal, L-J. and Bhave, N. S. "Resin. III. Synthesis, characterization, and ion-exchange properties of a 2, 2'-dihydroxybiphenyl-formaldehyde copolymer resin", J. Appl. Polym. Sci., 109, (2008), 508.

[14] Meenakshi, P., Noorjahan, S. E., Rajini, R., Venkateswarlu, U., Rose, C. and Sastry, T. P. "Mechanical and microstructure studies on the modification of CA film by blending with PS, Bulleti”, Material Science, 25 (2002), 25.

[15] Mohamed, N. A. and Fahmy, M. M. "Synthesis and Antimicrobial Activity of Some Novel Cross-Linked Chitosan Hydrogels”, Int. J. Mol. Sci., 13 (2012), 11194-11209.

[16] Mohan D, Pittman C Jr (2006) "Activated carbons and low cost adsorbents for remediation of tri- and hexavalent chromium from water". J Hazard Mater 137(2):762811 
Military Technical College

Kobry El-Kobbah, Cairo, Egypt

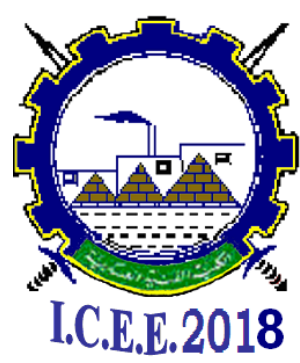

$9^{\text {th }}$ International Conference

on

Chemical \& Environmental

Engineering

3-5 April 2018

[17] Naoki Kano1, Kunihiro Tanabe, Meiling Pang, Yanling Deng and Hiroshi Imaizumi, Biosorption of Chromium from Aqueous Solution Using Chitosan, J. Chem. Chem. Eng. 8 (2014) 1049-1058.

[18] Nasernejad , B., Esslam, T., Zadeh, B. Bonakdar Pour, M. Esmaail Bygi, A. Zamani, "Camparison for biosorption modeling of heavy metals (Cr (III), Cu (II), Zn (II)) adsorption from wastewater by carrot residues", Pr. Bichem.,70(3-4), (2005), 13191322.

[19] Olayinka O. K. Olayinka, O. A . Oyedeji and O. A. Oyeyiola, Removal of chromium and nickel ions from aqueous solution by adsorption on modified coconut husk, African Journal of Environmental Science and Technology Vol. 3 (10), pp. 286-293, October, 2009)

[20] Puvvada YS, Vankayalapati S and Sukhavasi S (2012) Extraction of chitin from chitosan from exoskeleton of shrimp for application in the pharmaceutical industry, Int.Curr.Pharm.J.1(9):258-263.

[21] Saita, K., Nagaoka, S., Shirosaki, T., Horikawa, M., Matsuda, S. and Ihara, H. "Preparation and characterization of dispersible chitosan particles with borate crosslinking and their antimicrobial and antifungal activity", Carbohydr. Res, 349 (2012), 52-58.

[22] Samson O. Owalude Adedibu C. Tella, Removal of hexavalent chromium from aqueous solutions by adsorption on modified groundnut hull beni-suef university journal of basic and applied sciences 5 (2016) 377-388

[23] Suguna, M., Kumar, N. S., Reddy, A. S., Boddu, V. M. and Krishnaiah, A. "Biosorption of lead (II) from aqueous solution on glutaraldehyde cross-linked chitosan beads" Can. J. Chem. Eng., 89 (2011), 833-843.

[24] Tripathi, S., Mehrotra, G. K. and Dutta P. K. "Physicochemical and bioactivity of cross-linked chitosan-PVA film for food packaging applications" Int. J. Biol. Macromol, 45 (2009), 372. Varmaa, A. J., Deshpande, S. V. and Kennedy, J. F. "Metal complexation by chitosan and its derivatives: a review", Carbohydr. Polym. 55 (2004), 77-93.

[25] Wassel, M. A., Farg, R. S., Shehata, H. A., Anwar, A. M. and Mohamed H. A. "Removal of ferric ions $(\mathrm{Fe}+3)$ from natural solutions using modified chitosan" J. Advances Chemistry, 12(2), (2015), 3996-4008.

[26] Wassel, M. A., Swelam, A. A., Shama, S. A., Hamouda, A. A. and Desouky; A. M., Al-Azhar Bual, sci, 24(1), (2013), 33-45.

[27] Weber, W. J. and Morris, J. C. "Kinetic of adsorption on carbon from solution", Am. Soc. Chem. Eng., 89, (1963), 31.

[28] X. Han, Y. S. Wong, M. H. Wong, "Effects of anion species and concentration on the removal of $\mathrm{Cr}(\mathrm{VI})$ by a microalgal isolate, Chlorella miniata".;J. Hazard. Mater. 158, (2008), 615-620. 


\begin{tabular}{|c|c|}
\hline Proceeding of the $9^{\text {th }}$ ICEE Conference 3-5 April 2018 & NBC \\
Military Technical College \\
Kobry El-Kobbah, \\
Cairo, Egypt
\end{tabular}

[29] Xionga, L., Chena, C., Chen, . and Ni, J. "Adsorption of Pb(II) and Cd(II) from aqueous solutions using titanate nanotubes prepared via hydrothermal method", J. Hazard. Mater, 189, (2011), 741-748.

[30] Zhanga, Q., Pana, B., Zhange, W., Lva, L., Wang, X., Wua, J. and Taob, X. "Selective removal of $\mathrm{Pb}(\mathrm{II}), \mathrm{Cd}(\mathrm{II})$, and $\mathrm{Zn}(\mathrm{II})$ ions from waters by an inorganic exchanger $\mathrm{Zr}\left(\mathrm{HPO}_{3} \mathrm{~S}\right) 2$ ", J. Hazard. Mater, 170, (2009), 824-828 


\begin{tabular}{|c|c|}
\hline Proceeding of the $9^{\text {th }}$ ICEE Conference 3-5 April 2018 & NBC \\
Military Technical College \\
Kobry El-Kobbah, \\
Cairo, Egypt
\end{tabular}

Table (1): Adsorption parameters for Langmuir and Freundlich isotherms

\begin{tabular}{|c|c|c|c|c|c|c|c|}
\hline \multirow{2}{*}{$\mathrm{pH}$} & \multicolumn{4}{|c|}{ Langmuir parameters } & \multicolumn{3}{c|}{ Freundlich parameters } \\
\cline { 2 - 8 } & $\mathrm{Q}(\mathrm{mg} / \mathrm{g})$ & $\begin{array}{c}\mathrm{b} \\
(\mathrm{L} / \mathrm{mg})\end{array}$ & $\mathrm{RL}$ & $\mathrm{R}^{2}$ & $\mathrm{n}$ & $\begin{array}{c}\mathrm{kf} \\
(\mathrm{mg} / \mathrm{g})\end{array}$ & $\mathrm{R}^{\mathbf{2}}$ \\
\hline 2 & 12.48439 & 0.02090 & $84.260 \times 10^{-3}$ & 0.9988 & 2.29358 & 163.6440 & 0.9965 \\
\hline 3 & 15.77287 & 0.04067 & $45.150 \times 10^{-3}$ & 0.9999 & 3.57143 & 76.0852 & 0.9990 \\
\hline 4 & 16.33987 & 0.04553 & $40.526 \times 10^{-3}$ & 0.9998 & 3.85505 & 69.2309 & 0.9992 \\
\hline 7 & 14.92537 & 0.0331 & 0.061687 & 0.9996 & 3.16556 & 90.63585 & 0.9985 \\
\hline 8 & 14.64144 & 0.01972 & -0.10556 & 0.9981 & 2.96033 & 100.832376 & 0.9997 \\
\hline 9 & 15.57632 & 0.03836 & -0.10256 & 0.9996 & 3.24149 & 87.498378 & 0.9992 \\
\hline 10 & 15.77287 & 0.04020 & -0.10412 & 0.9996 & 3.68053 & 73.097075 & 0.9832 \\
\hline
\end{tabular}

Table (2): Adsorption parameters for Temkin and D-R isotherms

\begin{tabular}{|c|c|c|c|c|c|c|c|}
\hline \multirow{2}{*}{$\mathrm{pH}$} & \multicolumn{2}{|c|}{ Temkin parameters } & \multicolumn{4}{c|}{ D-R parameters } \\
\cline { 2 - 8 } & $\begin{array}{c}\mathrm{AT} \\
(\mathrm{L} / \mathrm{g})\end{array}$ & $\begin{array}{c}\mathrm{BT} \\
(\mathrm{J} / \mathrm{mol})\end{array}$ & $\mathrm{R}^{2}$ & $\mathrm{~B}$ & $\begin{array}{c}\mathrm{q} \circ \\
(\mathrm{mg} / \mathrm{g})\end{array}$ & $\begin{array}{c}\mathrm{E} \\
(\mathrm{KJ} / \mathrm{mol})\end{array}$ & $\begin{array}{c}\mathrm{AT} \\
(\mathrm{L} / \mathrm{g})\end{array}$ \\
\hline 2 & $6.39 \times 10-4$ & 7.8659 & 0.9982 & $2 \times 10-7$ & 6.540411 & 26.7261 & 0.9639 \\
\hline 3 & $2.48 \times 10-4$ & 5.6723 & 0.9996 & $2 \times 10-4$ & 17.81249 & 50.000 & 0.9996 \\
\hline 4 & $1.98 \times 10-4$ & 5.3478 & 0.9995 & $2 \times 10-4$ & 18.43775 & 50.000 & 0.9993 \\
\hline 7 & $33.8 \times 10-4$ & 6.2347 & 0.9991 & $7 \times 10-08$ & 12.09147 & 3779.645 & 0.9964 \\
\hline 8 & $39.47 \times 10-4$ & 6.5607 & 0.9998 & $6 \times 10-8$ & 13.20374 & 2886.7513 & 0.8864 \\
\hline 9 & 2.751468 & 5.8525 & 0.9989 & $9 \times 10-8$ & 10.88080 & 2357.0226 & 0.9621 \\
\hline 10 & $2.46 \times 10-4$ & 5.6690 & 0.9988 & $9 \times 10-8$ & 11.16071 & 2357.0226 & 0.9409 \\
\hline
\end{tabular}


Military Technical College Kobry El-Kobbah,

Cairo, Egypt

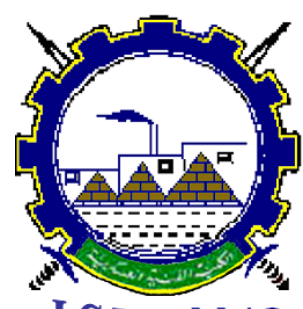

I.C.E.E.2018 $9^{\text {th }}$ International Conference

on

Chemical \& Environmental

Engineering

3-5 April 2018

Table (3: Adsorption parameters Pseudo first-order and Pseudo second-order

\begin{tabular}{|c|c|c|c|c|c|c|c|c|}
\hline \multirow[t]{2}{*}{ pH } & \multirow{2}{*}{$\begin{array}{c}\mathrm{T} \\
\mathrm{oC}\end{array}$} & \multicolumn{3}{|c|}{ Pseudo first-order } & \multicolumn{4}{|c|}{ Pseudo second-order } \\
\hline & & $\begin{array}{c}\text { qe, } 1 \\
(\mathrm{mg} / \mathrm{g})\end{array}$ & $\begin{array}{c}\text { K1 } \\
(\min -1)\end{array}$ & $\mathrm{R}^{2}$ & $\begin{array}{c}\mathrm{qe}, 2 \\
(\mathrm{mg} / \mathrm{g})\end{array}$ & $\begin{array}{c}\mathrm{K} 2 \\
(\mathrm{~g} / \mathrm{mg} \\
\mathrm{min})\end{array}$ & $\begin{array}{c}\mathrm{H} \\
(\mathrm{mg} / \mathrm{g} \min )\end{array}$ & $\mathrm{R}^{2}$ \\
\hline \multirow[t]{3}{*}{2} & 25 & 5.075728 & 0.045830 & 0.8104 & 20.449898 & 0.118600 & 5.882353 & 0.9996 \\
\hline & 35 & 0.038690 & 6.112234 & 0.9810 & 20.833300 & 0.108393 & 5.099439 & 1.0000 \\
\hline & 45 & 0.032703 & 4.555122 & 0.9029 & 21.929825 & 0.112396 & 6.075334 & 0.9997 \\
\hline \multirow[t]{3}{*}{3} & 25 & 10.57791 & 0.055733 & 0.9745 & 19.880716 & 0.114083 & 5.144033 & 0.9999 \\
\hline & 35 & 4.314197 & 0.033394 & 0.7901 & 20.040080 & 0.115116 & 5.321980 & 0.9992 \\
\hline & 45 & .449385 & 0.025103 & 0.9698 & 22.026432 & 0.096183 & 4.488330 & 0.9997 \\
\hline \multirow[t]{3}{*}{4} & 25 & 8.218641 & 0.037769 & 0.8116 & 17.857143 & 0.086824 & 2.403846 & 0.9975 \\
\hline & 35 & 6.596294 & 0.018654 & 0.9013 & 20.120724 & 0.06 & 1.569859 & 0.9941 \\
\hline & 45 & 7.857782 & 0.020727 & 0.9871 & 21.231423 & 0.059153 & 1.572871 & 0.9972 \\
\hline \multirow[t]{3}{*}{7} & 25 & 4.210174 & 0.038230 & 0.9780 & 19.60784 & 0.126907 & 6.19195 & 1.0000 \\
\hline & 35 & 4.347104 & 0.035236 & 0.9995 & 20.32520 & 0.120994 & 6.04230 & 1.0000 \\
\hline & 45 & 3.180534 & 0.020957 & 0.9106 & 21.05263 & 0.105038 & 4.88998 & 0.9999 \\
\hline \multirow[t]{3}{*}{8} & 25 & 1.762382 & 0.019345 & 0.9941 & 4068 & 0.17 & 10.4931794 & 1.0000 \\
\hline & 35 & 3.869011 & 0.033163 & 0.8297 & 20.1207244 & 0.130654 & 6.91085004 & 0.9990 \\
\hline & 45 & 29.53929 & 0.080835 & 0.7943 & 20.66 & 2014 & 5.3561864 & 0.9984 \\
\hline \multirow[t]{3}{*}{9} & 25 & 1.938653 & 0.021418 & 0.9798 & 19.4931774 & 0.159075 & 9.61538462 & 0.9991 \\
\hline & 35 & 1.735002 & 0.005758 & 0.9948 & 21.0970464 & 0.097675 & 4.2462845 & 0.9961 \\
\hline & 45 & 2.350715 & 0.010133 & 0.9615 & 21.5982721 & 0.454639 & 4.46428571 & 0.9980 \\
\hline \multirow[t]{3}{*}{10} & 25 & 1.534617 & 0.024872 & 0.882 & 19.7628459 & 0.1682 & 11.0497238 & 1.0000 \\
\hline & 35 & 2.236145 & 0.010364 & 0.9864 & 21.1864407 & 0.101558 & 4.62962963 & 0.9983 \\
\hline & 45 & 3.063374 & 0.024412 & 0.8662 & 21.8340611 & 0.110273 & 5.79710145 & 0.9994 \\
\hline
\end{tabular}


Military Technical College

Kobry El-Kobbah,

Cairo, Egypt

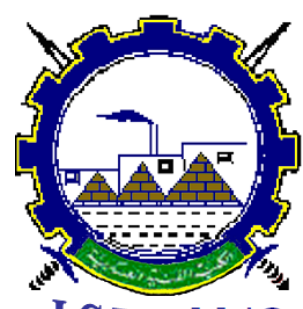

I.C.E.E.2018 $9^{\text {th }}$ International Conference

on

Chemical \& Environmental

Engineering

3-5 April 2018

Table (4): The intra-particle diffusion model (Weber-Marries) model for removal of $\mathrm{Cr}$ (III) by modified chitosan

\begin{tabular}{|c|c|c|c|c|}
\hline $\mathrm{pH}$ & $\mathrm{ToC}$ & Kid & $\mathrm{C}$ & $\mathrm{R} 2$ \\
\hline \multirow{3}{*}{2} & 25 & 0.4709 & 11.862 & 0.9491 \\
\hline & 35 & 0.6320 & 11.366 & 0.9562 \\
\hline & 45 & 0.7360 & 11.243 & 0.9993 \\
\hline \multirow{3}{*}{3} & 25 & 0.3162 & 15.971 & 0.8940 \\
\hline & 35 & 0.2403 & 16.858 & 0.8740 \\
\hline & 45 & 0.3605 & 17.326 & 0.9972 \\
\hline \multirow{3}{*}{4} & 25 & 0.3296 & 16.518 & 0.7502 \\
\hline & 35 & 0.3247 & 16.750 & 0.9524 \\
\hline & 45 & 0.2748 & 18.370 & 0.9718 \\
\hline \multirow{3}{*}{7} & 25 & 0.2653 & 16.372 & 0.8658 \\
\hline & 35 & 0.2727 & 16.942 & 0.9373 \\
\hline & 45 & 0.3355 & 16.801 & 0.9477 \\
\hline \multirow{3}{*}{8} & 25 & 0.1732 & 17.032 & 0.9977 \\
\hline & 35 & 0.2200 & 17.373 & 0.9175 \\
\hline & 45 & 0.2635 & 17.180 & 0.8946 \\
\hline \multirow{3}{*}{9} & 25 & 0.1777 & 17.374 & 0.9987 \\
\hline & 35 & 0.2409 & 17.482 & 0.7762 \\
\hline & 45 & 0.2925 & 17.564 & 0.8843 \\
\hline \multirow{3}{*}{10} & 25 & 0.1476 & 17.935 & 0.8975 \\
\hline & 35 & 0.2785 & 17.391 & 0.8985 \\
\hline & 45 & 0.2415 & 18.495 & 0.9472 \\
\hline
\end{tabular}


Military Technical College Kobry El-Kobbah,

Cairo, Egypt

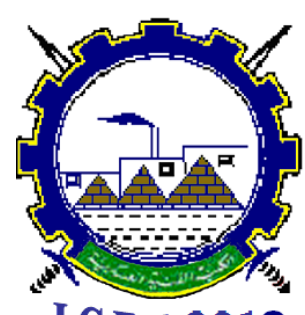

I.C.E.E.2018

\section{$9^{\text {th }}$ International Conference}

on

Chemical \& Environmental

Engineering

3-5 April 2018

Table (5) Thermodynamic parameters for removal of $\mathrm{Cr}$ (III) by modified chitosan

\begin{tabular}{|c|c|c|c|c|c|c|}
\hline $\mathrm{pH}$ & $\mathrm{T}^{\mathrm{o}} \mathrm{C}$ & $\begin{array}{c}\Delta \mathrm{G} \\
(\mathrm{KJ} / \mathrm{mol})\end{array}$ & $\begin{array}{c}\Delta \mathrm{S} \\
(\mathrm{J} / \mathrm{mol} \mathrm{K})\end{array}$ & $\begin{array}{c}\Delta \mathrm{H} \\
(\mathrm{KJ} / \mathrm{mol})\end{array}$ & A & $\begin{array}{c}\mathrm{Ea} \\
(\mathrm{KJ} / \mathrm{mol})\end{array}$ \\
\hline \multirow{3}{*}{2} & 25 & -398.138 & \multirow{3}{*}{10.00839} & \multirow{3}{*}{2602.033} & \multirow{3}{*}{0.048495} & \multirow{3}{*}{940.563} \\
\hline & 35 & -440.040 & & & & \\
\hline & 45 & -602.211 & & & & \\
\hline \multirow{3}{*}{3} & 25 & -349.774 & \multirow{3}{*}{11.73272} & \multirow{3}{*}{3172.622} & \multirow{3}{*}{0.000825} & \multirow{3}{*}{2858.770} \\
\hline & 35 & -382.537 & & & & \\
\hline & 45 & -589.867 & & & & \\
\hline \multirow{3}{*}{4} & 25 & -228.898 & \multirow{3}{*}{7.76195} & \multirow{3}{*}{2081.327} & \multirow{3}{*}{0.000183} & \multirow{3}{*}{6582.190} \\
\hline & 35 & -314.053 & & & & \\
\hline & 45 & -384.651 & & & & \\
\hline \multirow{3}{*}{7} & 25 & -342.911 & \multirow{3}{*}{6.834108} & \multirow{3}{*}{1694.31} & \multirow{3}{*}{0.000217} & \multirow{3}{*}{7151.62} \\
\hline & 35 & -408.024 & & & & \\
\hline & 45 & -480.465 & & & & \\
\hline \multirow{3}{*}{8} & 25 & -332.978 & \multirow{3}{*}{5.217035} & \multirow{3}{*}{1215.008} & \multirow{3}{*}{0.00021732} & \multirow{3}{*}{7151.62} \\
\hline & 35 & -405.445 & & & & \\
\hline & 45 & -436.849 & & & & \\
\hline \multirow{3}{*}{9} & 25 & -359.008 & \multirow{3}{*}{9.92359} & \multirow{3}{*}{2593.635} & \multirow{3}{*}{6468446.64} & \multirow{3}{*}{18407.2} \\
\hline & 35 & -470.692 & & & & \\
\hline & 45 & -557.969 & & & & \\
\hline \multirow{3}{*}{10} & 25 & -371.636 & \multirow{3}{*}{8.363884} & \multirow{3}{*}{2107.017} & \multirow{3}{*}{0.00017286} & \multirow{3}{*}{7302.02} \\
\hline & 35 & -496.527 & & & & \\
\hline & 45 & -537.789 & & & & \\
\hline
\end{tabular}




\begin{tabular}{|c|c|}
\hline Proceeding of the $9^{\text {th }}$ ICEE Conference 3-5 April 2018 & NBC \\
$\begin{array}{c}\text { Military Technical College } \\
\text { Kobry El-Kobbah, } \\
\text { Cairo, Egypt }\end{array}$ & $\begin{array}{c}\text { Chemical \& Environmental } \\
\text { Engineering }\end{array}$ \\
\hline I.C.E.E.2018 & 3-5 April 2018 \\
\hline
\end{tabular}

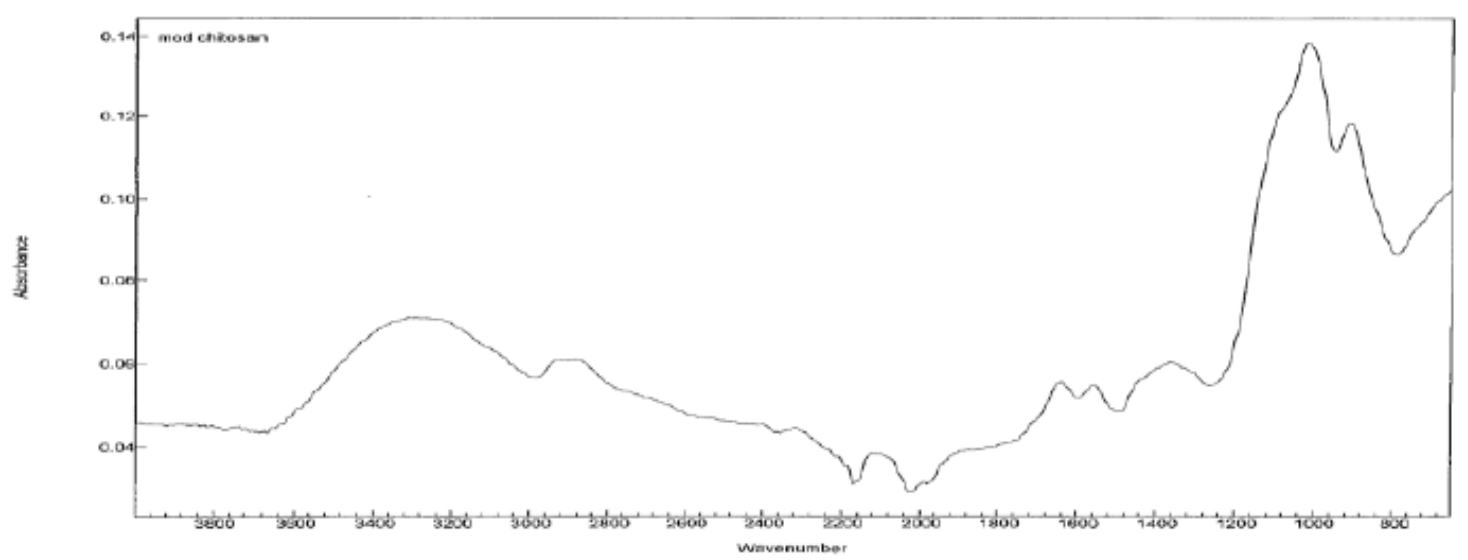

(a)

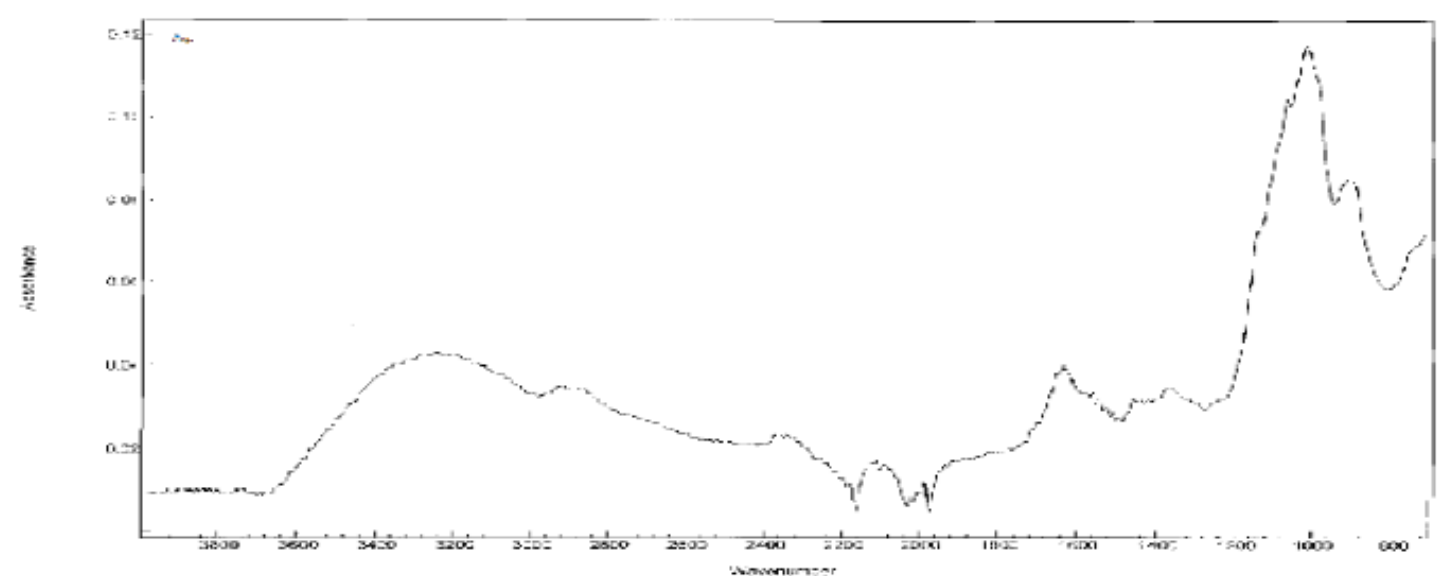

(b) 


\begin{tabular}{|c|c|}
\hline Proceeding of the $9^{\text {th }}$ ICEE Conference 3-5 April 2018 & NBC \\
$\begin{array}{c}\text { Military Technical College } \\
\text { Kobry El-Kobbah, } \\
\text { Cairo, Egypt }\end{array}$ & $\begin{array}{c}9^{\text {th }} \text { International Conference } \\
\text { on }\end{array}$ \\
& Chemical \& Environmental \\
& Engineering \\
\hline
\end{tabular}

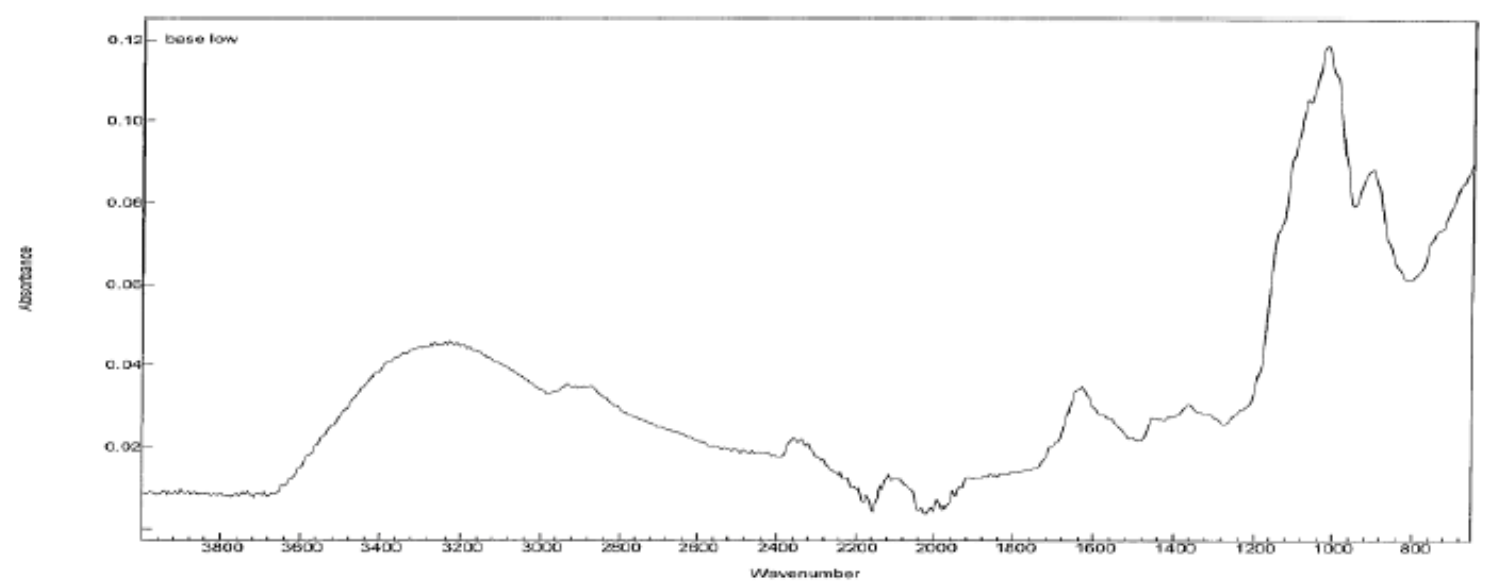

(c)

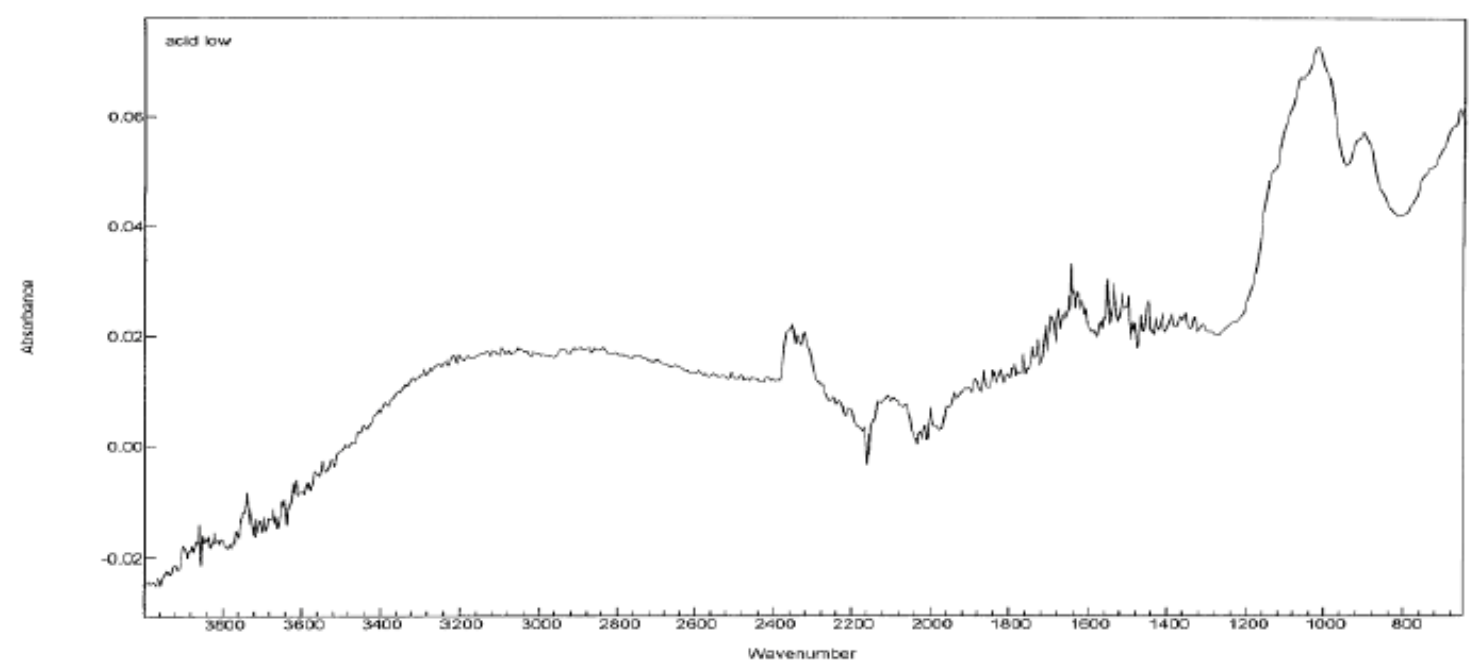

(d)

Fig.(1) FTIR of : (a) Modified Chitosan; (b) Modified Chitosan in neutral solution (pH 7); (c) in basic solution (pH 8); (d) in acidic solution (pH 4) 


\begin{tabular}{|c|c|}
\hline Proceeding of the $9^{\text {th }}$ ICEE Conference 3-5 April 2018 & NBC \\
Military Technical College \\
Kobry El-Kobbah, \\
Cairo, Egypt
\end{tabular}

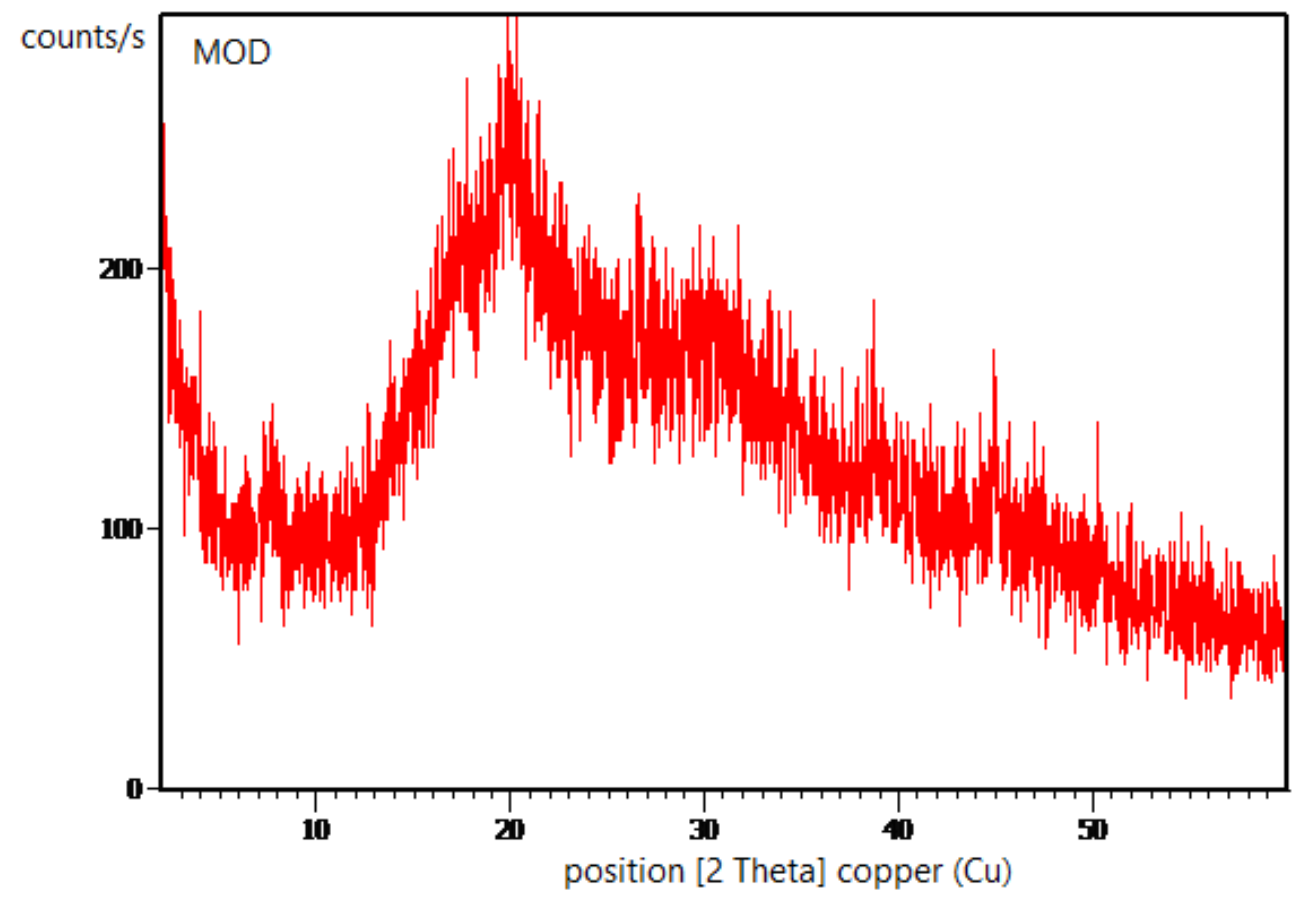

Fig. (2) X-ray diffraction of modified chitosan

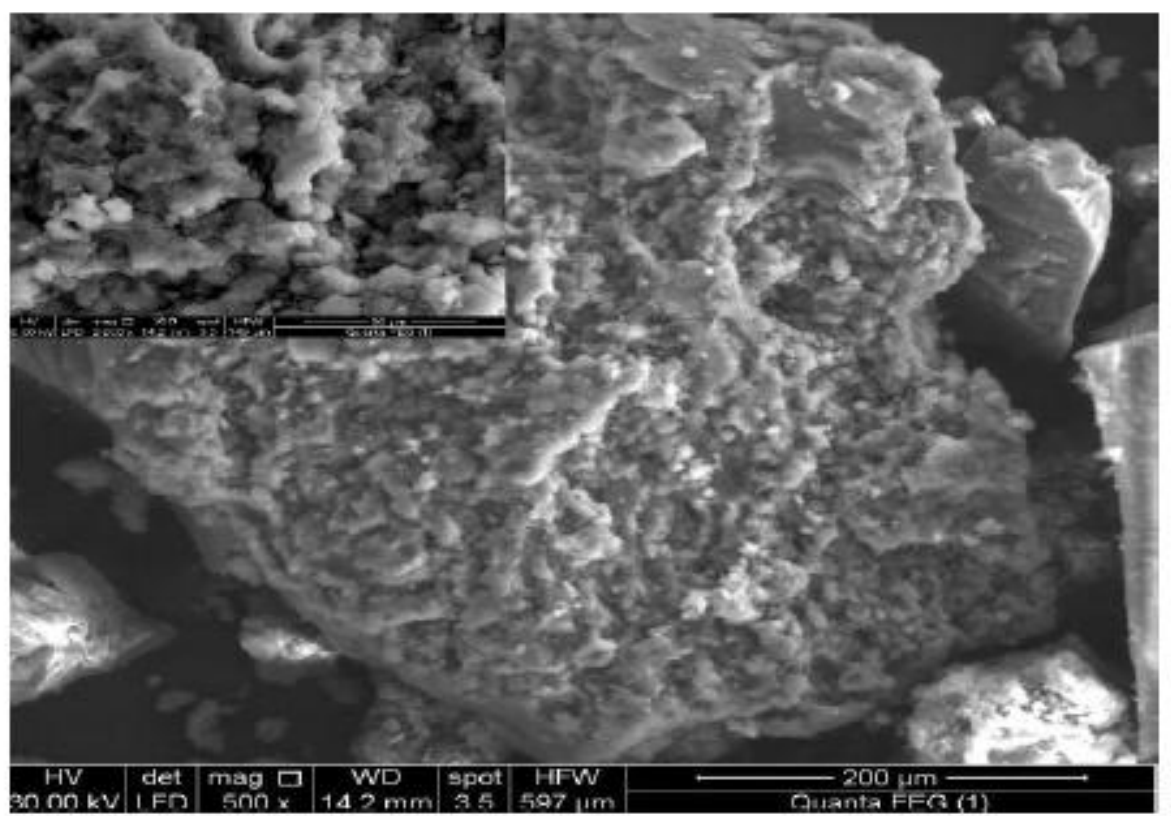

Fig. (3) Scanning electron microscope of modified Chitosan 


\begin{tabular}{|c|c|}
\hline Proceeding of the $9^{\text {th }}$ ICEE Conference 3-5 April 2018 & NBC \\
Military Technical College \\
Kobry El-Kobbah, \\
Cairo, Egypt
\end{tabular}

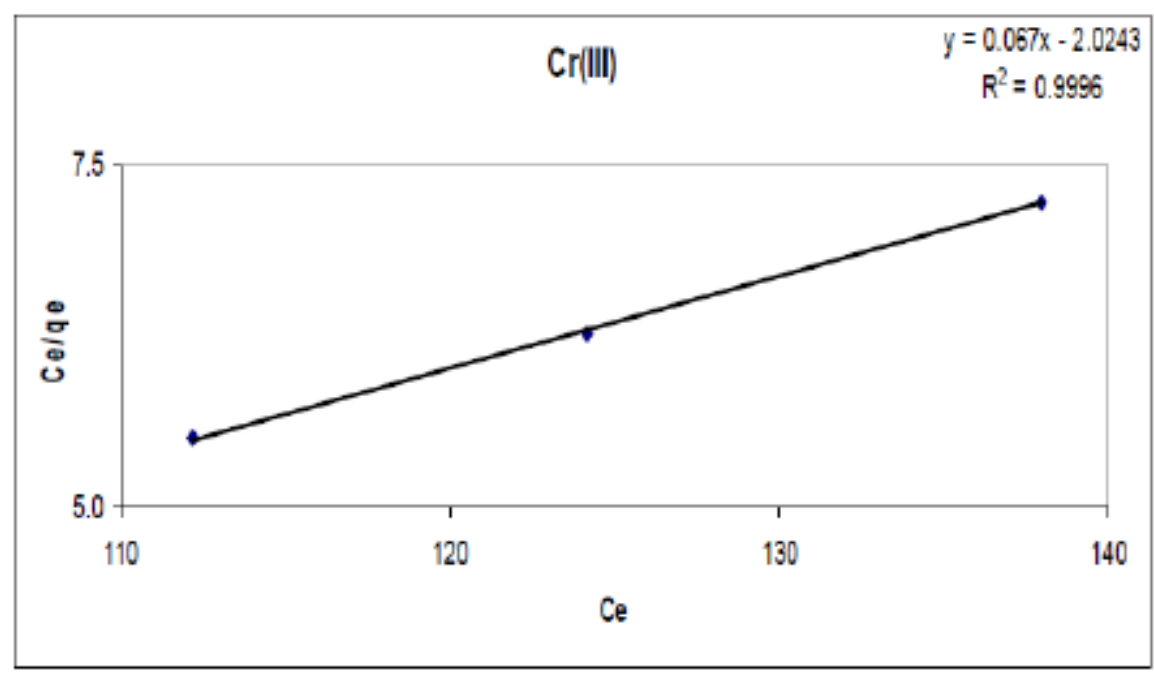

Fig.(4) Langmiur plot for removal of $\mathrm{Cr}$ (III) by modified chitosan at $\mathrm{pH}=7$

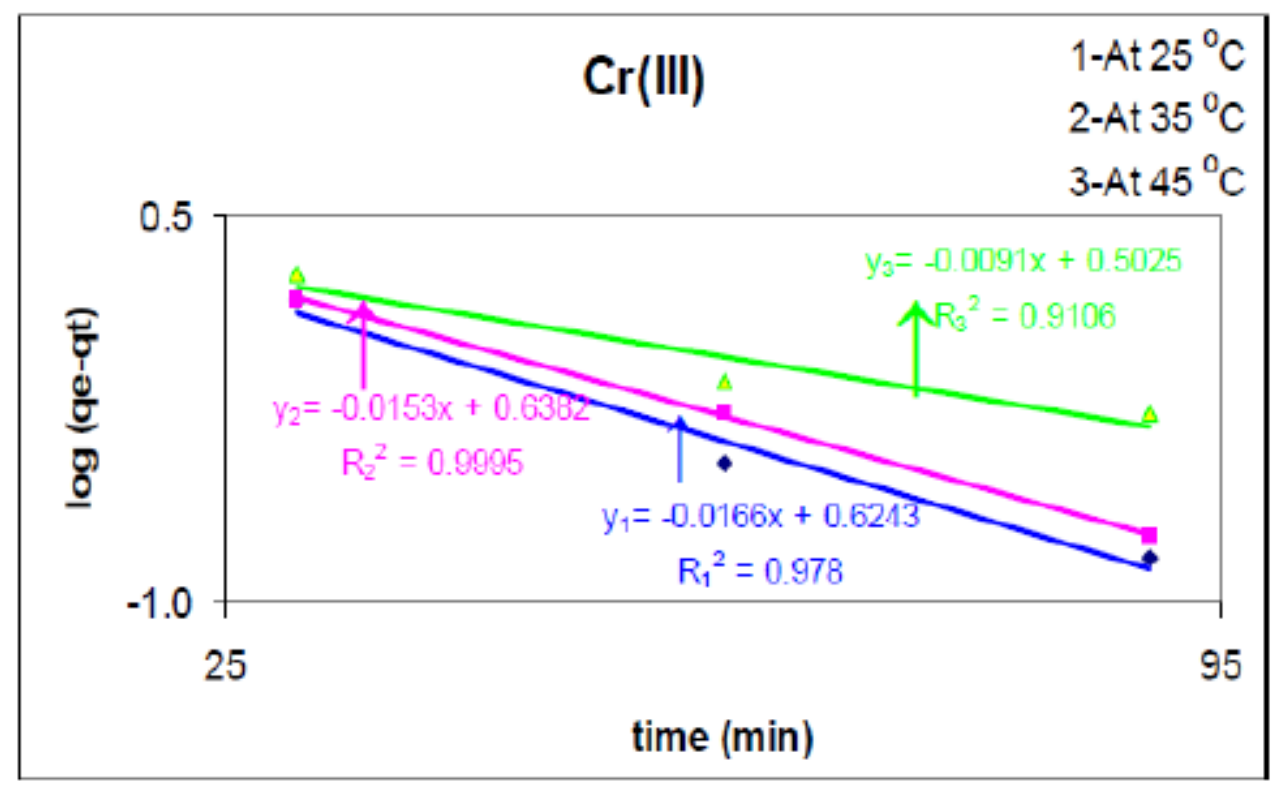

Fig. (5) Pseudo first order plot for removal of $\mathrm{Cr}$ (III) by modified chitosan at $\mathrm{pH}=7$ 


\begin{tabular}{|l|c|}
\hline Proceeding of the $9^{\text {th }}$ ICEE Conference 3-5 April 2018 & NBC \\
Military Technical College \\
Kobry El-Kobbah, \\
Cairo, Egypt
\end{tabular}

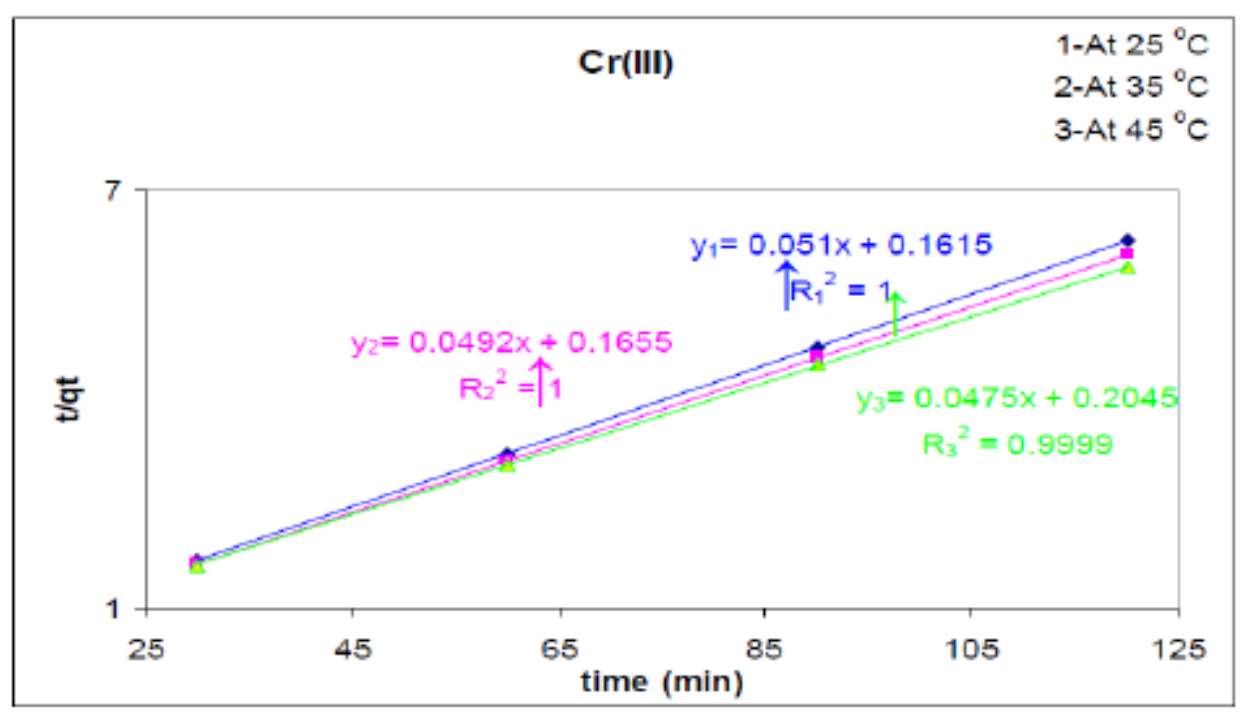

Fig. (6) Pseudo first order plot for removal of $\mathrm{Cr}$ (III) by modified chitosan at pH=7

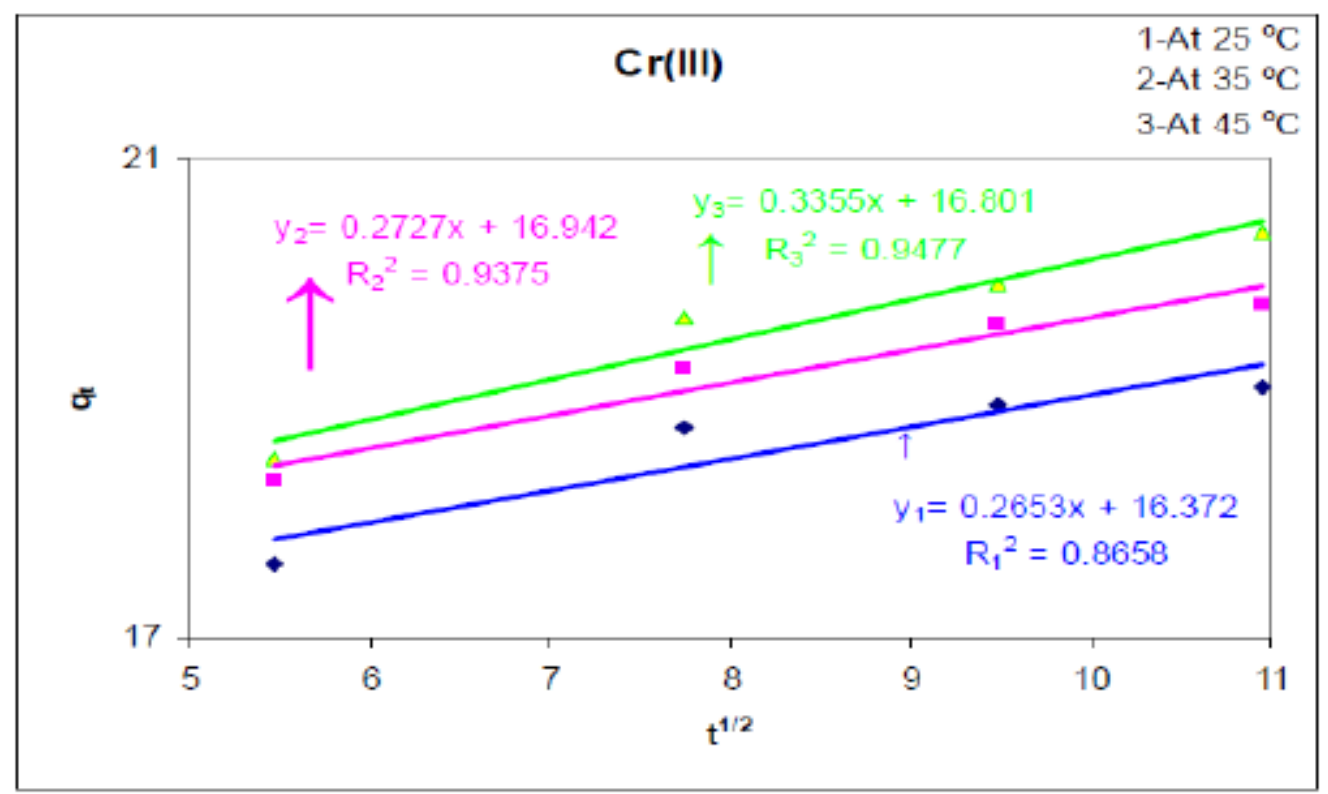

Fig. (7) The intra-particle diffusion model (Weber-Marries) model for removal of $\mathrm{Cr}$ (III) by modified chitosan at $\mathrm{pH}=7$ 


\begin{tabular}{|c|c|}
\hline Proceeding of the $9^{\text {th }}$ ICEE Conference 3-5 April 2018 & NBC \\
Military Technical College \\
Kobry El-Kobbah, \\
Cairo, Egypt
\end{tabular}

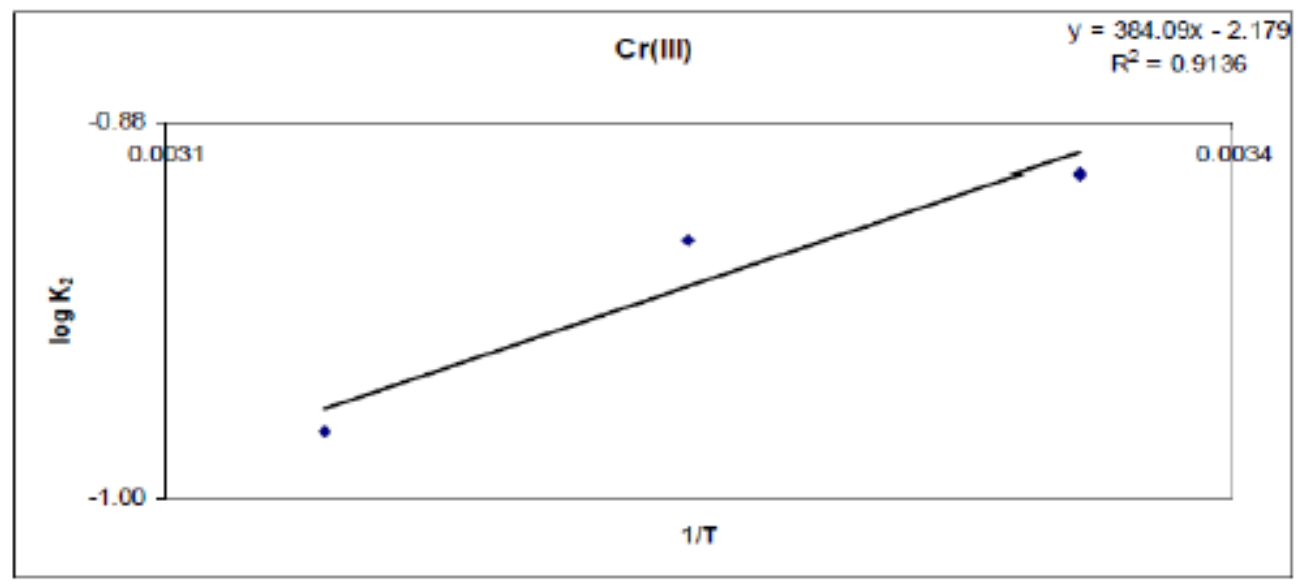

Fig. (8) Arrhenius equation for removal of $\mathrm{Cr}$ (III) by modified chitosan in aqueous solution 